\title{
ASSESSMENT OF ORAL HYGIENE IN ADULTS
}

\author{
Wojciech Skorupka', Karolina Żurek², Teresa Kokot ${ }^{3}$, Ewa Nowakowska-Zajdel ${ }^{3}$, Edyta Fatyga ${ }^{3}$, \\ Elżbieta Niedworok ${ }^{4}$, Małgorzata Muc-Wierzgoń ${ }^{3}$ \\ ${ }^{1}$ Private Health Care Centre, Family Dental Service-Multident, Mikołów, Poland \\ ${ }^{2}$ Private Dental Service, Katowice, Poland \\ ${ }^{3}$ Department of Internal Medicine, Medical University of Silesia, Katowice, Poland \\ ${ }^{4}$ Department of Human Nutrition, Medical University of Silesia, Katowice, Poland
}

\section{SUMMARY}

Objective: The aim of the research was to assess the oral hygiene habits in the elderly group of study population of Southern Poland.

Methods: The study was conducted in dental services in two selected cities in Southern Poland. The group of subjects consisted of 664 respondents (272 men, 392 women) aged 65 to 81 years. Oral hygiene was measured with the author's anonymous questionnaire consisting of twenty questions. Questions related to information on personal history and general health, comorbidities, dietary habits, alcohol consumption, smoking, taking drugs and the state of oral hygiene practices as frequency of visits to the dentist and the number of own teeth.

Results: The majority of the subjects had higher $n=240(36.1 \%)$ and secondary $n=219(33 \%)$ education and were predominantly $n=590$ (89\%) professionally inactive (retirees or pensioners). No significant differences were found between the groups: women and men. But there were differences in technologies used, the examined men significantly often used computer in comparison with the women's group. In total, $19.6 \%$ had own natural teeth only, $45.0 \%$ own teeth and dentures, $30.0 \%$ dentures only, and $5.4 \%$ neither teeth nor dentures. Majority of subjects brush their teeth or dentures only $1-2$ times a day $(80 \%)$ and visit the dentist less than once in 2 years or once a year $(75 \%)$. Women significantly more often stated use of a toothbrush and taking care of oral hygiene and compared to men, they declared higher number of own teeth.

Conclusion: People aged over 65 neglect hygiene and oral care. Women pay more attention to oral hygiene and they have more own teeth than men. The most frequent cause of oral hygiene neglect in the elderly could be gender, the socio-economic conditions, behaviour habits and lack of sufficient health education. The dentist may need to consult with the patient's GP the development of the appropriate personalised treatment plan for the elderly. Young dentists need to be educated in order to provide appropriate dental care to the elderly.

Key words: oral hygiene, elderly people, author's questionnaire, health education

Address for correspondence: Małgorzata Muc-Wierzgoń, Department of Internal Medicine, Medical University of Silesia, 7 Żeromskiego, 41 -902 Bytom, Poland. E-mail: mwierzgon@sum.edu.pl

\section{INTRODUCTION}

Oral epidemiological research indicates that most of the elderly in Poland as well as in other European countries and the United States do not have adequate oral hygiene habits (1-3). The oral cavity is an important part of the body, and it plays a crucial role in chewing, swallowing, speaking, and in forming facial expressions as well as maintaining nutritional status, systemic health, and self-esteem. Oral hygiene is directly linked to systemic infections, autoimmune disorders, chronic cardiovascular disease, glucose control in diabetes, nutritional intake and other diseases (4-7). These chronic diseases can affect a person's quality of life, especially the ability to eat, speak, taste, and swallow; in addition, they can cause the psychological instability and significant pain.

Age-related lesions and dental problems stem from the occurrence of certain factors including the following: alveolar process atrophy, dental caries, reduced daily salivation and xerostomia, tooth loss, oral cancer, denture acceptance difficulties resulting from advanced oral mucosal diseases, lesions in the denture bearing areas (alveolar and osseous) and local and systemic diseases (8). Many of these are the sequelae of neglect throughout the early years of life (i.e.cariogenic diet, lack of prevention awareness and habits like smoking and/or tobacco, pan, and betel nut chewing) (9). Vellappally-Sajith et al. (10) describe different forms of tobacco usage and its direct relationship with the prevalence of dental diseases. Older adults are likely to take medications that can impact oral health and affect dental treatment. Hundreds of common medications, including antihistamines, diuretics, pain killers, high blood pressure medications and antidepressants, can cause side effects such as dry mouth, soft tissue changes, taste changes, and gingival overgrowth $(11,12)$. Women who are menopausal or post-menopausal may experience changes in their mouths. Recent studies suggest that estrogen deficiency can place post-menopausal women at higher risk for severe periodontal disease and tooth loss. In addition, hormonal changes in older women may result in oral discomfort including dry mouth, pain and burning sensations in the gingiva and altered taste (13).

Many analytical studies in public health have examined sociodemographic characteristics such as age, race, sex, and socioeconomic status; relatively few have investigated the influence of behaviour and lifestyle characteristics on the oral health of older populations $(2,14-16)$. 
The aim of the research was to assess the state of dentition and hygiene habits in the elderly group of study population of Southern Poland.

\section{MATERIALS AND METHODS}

\section{Subjects}

Research was conducted in Dental Services in two selected cities in Southern Poland (Katowice and Mikołów). The group of subjects consisted of 664 people ( 272 men, 392 women) aged 65 and older with a maximum age of 81 . The mean age of the subjects was $72.2 \pm 8.6$. The patients were included into the study group if older than 65 years and agreed to participate after giving informed consent. The study group profiles in demographic and socio-economic aspects are presented in Table 1. The data included gender, age, marital status, education and use of technology. The respondents were divided into 3 groups: aged 65-69, $\mathrm{n}=273(41.1 \%) ; 70-74, \mathrm{n}=206(31 \%)$; and $\geq 75, \mathrm{n}=185(27.9 \%)$.

\section{Questionnaire}

Anonymous questionnaire designed for the purpose of this study consisted of twenty questions. Questions related to information on personal history and general health, comorbidities, dietary habits, alcohol consumption, smoking, taking drugs and the state of oral hygiene practices, frequency of visits to the dentist, and the number of own teeth. Some of the questions were open questions and in the rest of them patients were asked to mark 'yes' or 'no'.

The questionnaires were filled in during the patient's visit to the Dental Services by the dentists from January to December 2010. They underwent dental examination as well. All patients gave their consent to participate in an anonymous questionnaire.

The oral cavity conditions and results of oral health examination were not analysed in this paper.

\section{Statistical Analysis}

Much of the collected material was descriptive in nature. Statistical analysis of the results included descriptive analyses, the test of independence $\chi^{2}$ (assessed the relationship between the study groups, gender, socio-economic status, concomitant disease, dietary habits and oral hygiene habits of seniors). The level of significance was $\mathrm{p}<0.05$.

\section{RESULTS}

The majority of the subjects had higher $(n=240,36.1 \%)$ and secondary $(n=219,33 \%)$ education and were predominantly $(\mathrm{n}=590,89 \%)$ professionally inactive (retirees or pensioners). No significant differences were found between female and men. The only differences found concerned the use of technology. Examined group of men used computer significantly more often than the female group $(\mathrm{p}<0.001)$.

Diseases most commonly reported by the subjects were the following: arterial hypertension (88\%), osteoarthritis (82\%), obesity $(62 \%)$, coronary heart disease $(55 \%)$, respiratory disorders (43\%), diseases of peripheral vessels (34\%), type 2 diabetes (33\%) and mental illness (2\%). There were no significant differences between examined groups.

Out of 664 patients, 221 (33.3\%) had never smoked, 224 $(33.7 \%)$ smoked in the past and $219(33 \%)$ patients were smokers who continued to smoke after examination. Majority of study group members drink coffee every day. Only 73 patients (69 men and 4 women) (11\%) declared that they abused alcohol in the past. All examined people stated that they were not dieting (insufficient vegetables and fruits intake per day, too much fat and callories).

Additionally, all the patients were divided into 3 age groups, but the statistically significant differences were observed only between genders: female $(n=392,59 \%)$ and $\operatorname{men}(n=272,41 \%)$ (Tables 2, 3).

Not all respondents $(n=113,17 \%)$ reported that they clean their teeth or dentures using a toothbrush or denture brush. They did

Table 1. Demographic and socio-economic characteristics of the study group

\begin{tabular}{|c|c|c|c|c|c|c|c|c|}
\hline & & \multicolumn{2}{|c|}{ Patients } & \multicolumn{2}{|c|}{ Male } & \multicolumn{2}{|c|}{ Female } & $p$ \\
\hline \multicolumn{2}{|l|}{ N } & 664 & $100.0 \%$ & 272 & $41.0 \%$ & 392 & $59.0 \%$ & $<0.001$ \\
\hline \multirow{3}{*}{ Age } & $65-69$ & 273 & $41.1 \%$ & 116 & $42.6 \%$ & 157 & $40.1 \%$ & \multirow{3}{*}{$<0.05$} \\
\hline & $70-74$ & 206 & $31.0 \%$ & 95 & $35.0 \%$ & 111 & $28.3 \%$ & \\
\hline & $\geq 75$ & 185 & $27.9 \%$ & 61 & $22.4 \%$ & 124 & $31.6 \%$ & \\
\hline \multirow{2}{*}{ Marital status } & Single/widowed/divorced & 425 & $64.0 \%$ & 149 & $54.8 \%$ & 285 & $72.7 \%$ & \multirow{2}{*}{$<0.001$} \\
\hline & Married & 239 & $36.0 \%$ & 123 & $45.2 \%$ & 107 & $27.3 \%$ & \\
\hline \multirow{4}{*}{ Education level } & Higher & 240 & $36.1 \%$ & 128 & $47.1 \%$ & 112 & $28.6 \%$ & \multirow{4}{*}{ NS } \\
\hline & Secondary & 219 & $33.0 \%$ & 73 & $26.8 \%$ & 146 & $37.2 \%$ & \\
\hline & Vocational & 132 & $19.9 \%$ & 52 & $19.1 \%$ & 80 & $20.4 \%$ & \\
\hline & Primary & 73 & $11.0 \%$ & 19 & $7.0 \%$ & 54 & $13.8 \%$ & \\
\hline \multirow{4}{*}{ Use of technology } & Automated teller machine only & 132 & $20.0 \%$ & 57 & $20.9 \%$ & 75 & $19.1 \%$ & \multirow{4}{*}{$<0.001$} \\
\hline & Computer only & 120 & $18.0 \%$ & 71 & $26.1 \%$ & 49 & $12.5 \%$ & \\
\hline & Both & 259 & $39.0 \%$ & 118 & $43.4 \%$ & 141 & $36.0 \%$ & \\
\hline & Neither & 153 & $23.0 \%$ & 26 & $9.6 \%$ & 127 & $32.4 \%$ & \\
\hline
\end{tabular}


it mostly 1 or 2 times a day $(n=531,80 \%)$. Women significantly more often stated the use of toothbrush and taking greater care of oral hygiene $(\mathrm{p}<0.001)$ (Table 2$)$.

Almost $30 \%$ of the study participants changed their toothbrush more frequently than every 3 months. Approximately $28 \%$ of the seniors were not sure how often they changed their toothbrushes. The others change it once a year. All respondents did not go to the dentist too often. The vast majority of the patients $(n=478$, $72 \%$ ) visited the dentist once a year. No significant differences were found between the groups.

The reason for the last visit of the dentist were toothache $n=352(53 \%)$ and need for change of the dentures $(n=133$, $20 \%$ ) (Table 2). The women took greater care of oral cavity and visit dental offices more often than men did. In total, $19.6 \%$ had own natural teeth only, $45.0 \%$ own teeth and dentures, $30.0 \%$ dentures only, and $5.4 \%$ neither teeth nor dentures. The number of the natural teeth in the study patients were presented in Table 3.

\section{DISCUSSION}

Old age generally exacerbates specific health problems. Agerelated dental symptoms, the tooth loss, weakened immune system and side effects of medicine have a long-term impact on general health and the state of the oral cavity. Therefore, the elderly, who are frequently chronically ill, constitute a high-risk group that requires special care regarding the health of the oral cavity. Bearing in mind how important dentition is for general health, it is necessary to take preventive measures and successfully promote and implement prophylaxis $(17,18)$. Among the over 65 examined population, approximately $80 \%$ suffered from at least one chronic disease, hearing loss, vision impairment or taste disorders. Elderly people usually take five or more medications per day.

The research showed that the elderly people do brush their teeth; however, the majority ( $80 \%$ ) does it only once or twice per day. Moreover, they did not go often to the dentist. As many as $72 \%$ of the subjects visit the dentist once a year. The barriers to proper oral hygiene in elderly people including visit to the dentist are: low socio-economic status (income), lack of fund, chronic system disease, age, and fear of pain.

The respondents aged over 65 used both upper and lower dentures, and only a fraction of them still have their own teeth ( 239 , i.e. $39 \%$ stated ' 0 own teeth').

In other research, the reasons for tooth loss were as follows: caries, parodontopathy, and trauma $(18,19)$. While the National Institute of Dental and Craniofacial Research (NIDCR) reported that the prevalence of both partial and total tooth loss in seniors has decreased from the early 1970's, seniors over 65 have lost an average of 13 teeth (including wisdom teeth), and $26 \%$ of seniors over 65 have no remaining teeth (20).

This study showed that the subjects of both genders were satisfied with the dentures they were using. They claimed that the denture makes eating easier, improves physical appearance and has a positive influence on the psyche. The success of prosthetic treatment, full adaptation and patient satisfaction also depended on the patient's general and oral hygiene.

However, the dentist's skills and knowledge are just as important as the state of the patient's oral cavity. By applying the best

Table 2. Oral hygiene practices of the elderly patients

\begin{tabular}{|c|c|c|c|c|c|c|c|c|}
\hline \multirow{3}{*}{$\begin{array}{l}\text { Practice of oral } \\
\text { hygiene }\end{array}$} & \multirow[b]{2}{*}{ Yes } & \multicolumn{2}{|c|}{ Patients } & \multicolumn{2}{|c|}{ Male } & \multicolumn{2}{|c|}{ Female } & \multirow{3}{*}{$\begin{array}{c}p \\
<0.001\end{array}$} \\
\hline & & 365 & $55.0 \%$ & 103 & $42.6 \%$ & 262 & $66.8 \%$ & \\
\hline & No & 299 & $45.0 \%$ & 169 & $57.4 \%$ & 130 & $33.2 \%$ & \\
\hline \multirow{2}{*}{ Use a toothbrush } & Yes & 551 & $83.0 \%$ & 192 & $70.6 \%$ & 360 & $91.8 \%$ & \multirow{2}{*}{$<0.001$} \\
\hline & No & 113 & $17.0 \%$ & 80 & $29.4 \%$ & 33 & $8.4 \%$ & \\
\hline \multirow{2}{*}{$\begin{array}{l}\text { Received health edu- } \\
\text { cation of oral hygiene }\end{array}$} & Yes & 451 & $68.0 \%$ & 175 & $64.3 \%$ & 276 & $70.4 \%$ & \multirow{2}{*}{ NS } \\
\hline & No & 212 & $32.0 \%$ & 97 & $35.7 \%$ & 116 & $29.6 \%$ & \\
\hline \multirow{2}{*}{$\begin{array}{l}\text { Regular tooth brushing } \\
\text { after meals }\end{array}$} & Yes & 27 & $4.0 \%$ & 12 & $4.4 \%$ & 15 & $3.8 \%$ & \multirow{2}{*}{ NS } \\
\hline & No & 637 & $96.0 \%$ & 260 & $95.6 \%$ & 377 & $96.2 \%$ & \\
\hline \multirow{3}{*}{$\begin{array}{l}\text { Frequency of oral } \\
\text { hygiene per day }\end{array}$} & Never & 133 & $20.0 \%$ & 87 & $32.0 \%$ & 46 & $11.7 \%$ & \multirow{3}{*}{$<0.001$} \\
\hline & Once & 511 & $77.0 \%$ & 178 & $65.4 \%$ & 333 & $85.0 \%$ & \\
\hline & Two times or more & 20 & $3.0 \%$ & 7 & $2.6 \%$ & 13 & $3.3 \%$ & \\
\hline \multirow{5}{*}{$\begin{array}{l}\text { Frequency of visit to } \\
\text { the Dentist Service }\end{array}$} & More than once every 6 months & 20 & $3.0 \%$ & 9 & $3.3 \%$ & 11 & $2.8 \%$ & \multirow{5}{*}{ NS } \\
\hline & Once every 6 months & 33 & $5.0 \%$ & 15 & $5.5 \%$ & 18 & $4.6 \%$ & \\
\hline & Once every 6-11 months & 113 & $17.0 \%$ & 51 & $18.8 \%$ & 62 & $15.8 \%$ & \\
\hline & Once a year & 478 & $72.0 \%$ & 190 & $69.8 \%$ & 288 & $73.5 \%$ & \\
\hline & Once every two years & 20 & $3.0 \%$ & 7 & $2.6 \%$ & 13 & $3.3 \%$ & \\
\hline \multirow{4}{*}{$\begin{array}{l}\text { Reason for the last } \\
\text { visit to the dentist }\end{array}$} & Toothache & 352 & $53.0 \%$ & 178 & $65.4 \%$ & 174 & $44.4 \%$ & \multirow{4}{*}{$<0.001$} \\
\hline & Routine exam & 53 & $8.0 \%$ & 20 & $7.4 \%$ & 33 & $8.4 \%$ & \\
\hline & Dental extraction & 126 & $19.0 \%$ & 37 & $13.6 \%$ & 89 & $22.7 \%$ & \\
\hline & Need for change of the prosthesis & 133 & $20.0 \%$ & 37 & $13.6 \%$ & 96 & $24.5 \%$ & \\
\hline
\end{tabular}


Table 3. Number of own teeth in the study groups

\begin{tabular}{|c|c|c|c|c|c|c|c|c|}
\hline & & \multicolumn{2}{|c|}{ Patients } & \multicolumn{2}{c|}{ Male } & \multicolumn{2}{c|}{ Female } & \multicolumn{1}{c|}{$p$} \\
\hline \multirow{3}{*}{ Number of own teeth } & 0 & 239 & $36.0 \%$ & 106 & $39.0 \%$ & 133 & $33.9 \%$ & \\
\cline { 2 - 10 } & $<1-10>$ & 103 & $15.5 \%$ & 83 & $30.5 \%$ & 20 & $5.1 \%$ & $<0.001$ \\
\cline { 2 - 9 } & $<11-32>$ & 322 & $48.5 \%$ & 83 & $30.5 \%$ & 239 & $61 \%$ \\
\hline
\end{tabular}

treatment and providing patients with proper hygiene instructions, the dentist may contribute to improving both oral and systemic health $(21,22)$. According to the many studies the oral health in elderly patients was unsatisfactory. Impact on this state of afairs was often inadequate care and prevention in earlier periods of life. All dental activity should be primarily aimed at saving as many teeth as possible and delay prosthetic treatment until old age. Hence, an aging society creates new tasks for the health care system which predominantly consist of prophylaxis and promotion (23). The aim of the study was to asses oral hygiene, frequency of visit to the dentist and the number of own teeth in a sample of elderly population in Southern Poland. The findings of our research suggested that the oral problems are very important in elderly patients. The results showed that the patients shoud be educated to change their habits by planning preventative health programme. Further research is needed.

The findings of this study do suggest that:

1. People aged over 65 neglect hygiene and oral care.

2. Women more often practice oral hygiene and they have more own teeth than men.

3. The most frequent cause of oral hygiene neglect in the elderly could be gender, the socio-economic conditions, behaviour habits and lack of sufficient health education.

4. The dentist may need to consult with the patient's GP the development of the appropriate personalised treatment plan in elderly patients.

5. Young dentists need to be educated in order to provide appropriate dental care to the elderly.

\section{Conflict of interests}

None declared

\section{REFERENCES}

1. Adachi M, Ishihara K, Abe S, Okuda K. Professional oral health care by dental hygienists reduced respiratory infections in elderly persons requiring nursing care. Int J Dent Hyg. 2007 May;5(2):69-74.

2. Pyle MA, Stoller EP. Oral health disparities among the elderly: interdisciplinary challenges for the future. J Dent Educ. 2003 Dec;67(12):1327-36.

3. Coleman P. Improving oral health care for the frail elderly: a review of widespread problems and best practices. Geriatr Nurs. 2002 JulAug;23(4):189-99.

4. Mojon P. Oral health and respiratory infection. J Can Dent Assoc. 2002 Jun;68(6):340-5
5. Taylor GW, Loesche WJ, Terpenning MS. Impact of oral diseases on systemic health in the elderly: diabetes mellitus and aspiration pneumonia. J Public Health Dent. 2000 Fall;60(4):313-20.

6. Li X, Kolltveit KM, Tronstad L, Olsen I. Systemic diseases caused by oral infection. Clin Microbiol Rev. 2000 Oct;13(4):547-58.

7. Zubelewicz-Szkodzińska B, Szkodziński J, Danikiewicz A, Błażelonis A, Muc-Wierzgoń M, Muryn Z. Effects of simvastatin in old patients with hypercholesterolemia. Kardiol Pol. 2003;59:470-3. (In Polish.)

8. Sapp JP, Eversole LR, Wysocki GP. Contemporary oral and maxillofacial pathology. 2nd ed. St. Louis: Mosby; 2004.

9. Genco RJ. Current view of risk factors for periodontal diseases. J Periodontol. 1996 Oct;67(10 Suppl):1041-9.

10. Vellappally S, Fiala Z, Šmejkalová J, Jacob V, Shriharsha P. Influence of tobacco use in dental caries development. Cent Eur J Public Health. 2007 Sep;15(3):116-21.

11. Moynihan P, Petersen PE. Diet, nutrition and the prevention of dental diseases. Public Health Nutr. 2004 Feb;7(1A):201-26.

12. Shay K, Ship JA. The importance of oral health in the older patient. J Am Geriatr Soc. 1995 Dec;43(12):1414-22.

13. Famili P, Cauley J, Suzuki JB, Weyant R. Longitudinal study of periodontal disease and edentulism with rates of bone loss in older women. J Periodontol. 2005 Jan;76(1):11-5.

14. Petersen PE, Yamamoto T. Improving the oral health of older people: the approach of the WHO Global Oral Health Programme. Community Dent Oral Epidemiol. 2005 Apr;33(2):81-92.

15. Petersen PE, Bourgeois D, Bratthall D, Ogawa H. Oral health information systems - towards measuring progress in oral health promotion and disease prevention. Bull World Health Organ. 2005 Sep;83(9):686-93.

16. Steele JG, Sanders AE, Slade GD, Allen PF, Lahti S, Nuttall N, et al. How do age and tooth loss affect oral health impacts and quality of life? A study comparing two national samples. Community Dent Oral Epidemiol. 2004 Apr;32(2):107-14

17. Hodačová L, Šmejkalová J, Čermáková E, Slezák R, Jacob V, Hlaváčková E. Oral health-related quality of life in Czech population. Cent Eur J Public Health. 2010 Jun;18(2):76-80.

18. Jainkittivong A, Aneksuk V, Langlais RP. Oral mucosal conditions in elderly dental patients. Oral Dis. 2002 Jul;8(4):218-23.

19. Glazar I, Urek MM, Brumini G, Pezelj-Ribaric S. Oral sensorial complaints, salivary flow rate and mucosal lesions in the institutionalized elderly. J Oral Rehabil. 2010 Feb;37(2):93-9.

20. National Institute of Dental and Craniofacial Research. Tooth loss in seniors (age 65 and over) [Internet]. Bethesda: NIDCR; 2011 [cited 2012 May 16]. Available from: http://www.nidcr.nih.gov/DataStatistics/ FindDataByTopic/ToothLoss/ToothLossSeniors65andOlder.htm.

21. Ahluwalia K. Oral health care for the elderly: more than just dentures. Am J Public Health. 2004 May;94(5):698.

22. Talwar M, Chawla HS. Geriatric dentistry: is rethinking still required to begin undergraduate education? Indian J Dent Res. 2008 AprJun;19(2):175-7.

23. Christensen LB, Petersen PE, Krustrup U, Kjøller M. Self-reported oral hygiene practices among adults in Denmark. Community Dent Health. 2003 Dec;20(4):229-35. 